\title{
Estudio y análisis de situaciones meteorológicas asociadas a la convección severa en el noreste peninsular
}

https://doi.org/10.31978/639-19-010-0.293

\author{
Peio Oria Iriarte ${ }^{1}$ (poriai@aemet.es)
}

${ }^{1}$ AEMET / Delegación Territorial en Navarra

\begin{abstract}
RESUMEN
Del estudio de la distribución de ecos de reflectividad 2D del radar de Zaragoza se han obtenido dos episodios convectivos con efectos severos en superficie correspondientes a los meses comprendidos entre abril y octubre del periodo 2008-2017. Para estas situaciones se han analizado algunos campos de reanálisis (obtenidos del ERA-Interim de ECMWF (Centro Europeo de Predicción a Medio Plazo)) relacionados con la convección profunda (altura geopotencial y temperatura en niveles altos, convergencias de humedad, etc.) y otros parámetros postprocesados (gradientes térmicos verticales, hodógrafas, etc.). También se muestran registros provenientes de datos obtenidos por estaciones meteorológicas automáticas (EMA).
\end{abstract}

PALABRAS CLAVE: convección severa; reflectividad radar; noreste peninsular; ERA-Interim; EMA.

\section{INTRODUCCIÓN}

La convección severa y/o organizada se pronostica principalmente a través de los campos de salida de los modelos numéricos. Estos tratan de resolver físicamente y computar matemáticamente los mecanismos de iniciación de la convección que potencian los ascensos de aire: la divergencia en niveles altos debido a la generación de vorticidad o a la difluencia de las líneas de flujo, los ascensos frontales o la convergencia de humedad en la capa límite, bien sea por factores asociados al relieve o por la advección de origen dinámico como, por ejemplo, la asociada a una mesobaja mediterránea. Por otro lado, en un horizonte de nowcasting el seguimiento de células convectivas se realiza básicamente con ayuda de herramientas de teledetección satelitales y de radar.

El desarrollo de la convección severa en el cuadrante nororiental peninsular va ligado en numerosas ocasiones al forzamiento sinóptico originado por la aproximación de una dana o, con mayor frecuencia, por el paso de una vaguada atlántica en altura y del frente frío asociado. En estas situaciones es habitual que el flujo del suroeste se intensifique con la altura. Otros factores que posibilitan la iniciación de la convección son el fuerte calentamiento diurno durante primavera y verano en el tramo medio del valle del Ebro, el cual favorece un gradiente térmico vertical propicio para los ascensos y el viento ageostrófico húmedo y cálido que remonta el valle en dirección sureste-noroeste desde el Mediterráneo y que suele ser potenciado además por la baja térmica peninsular. Con esta configuración el perfil de cizalladura es a menudo favorable para el desarrollo de estructuras convectivas profundas y organizadas. Por otro lado, las zonas montañosas de esta región (Ibérica riojana, Moncayo, serranías turolenses, macizo de Cinco Villas, Prepirineo, etc.) contribuyen al disparo de la convección y originan líneas de convergencia y fronteras mesoescalares de masas de aire (PASCUAL et al., 2014, Pascual et al., 2015). 
Al tener clasificada la distribución de ecos de reflectividad radar 2D superiores a 54 dBZ (véase contribución «Climatología de células convectivas con efectos severos asociados en el noreste peninsular» en este mismo volumen) e identificados algunos de los episodios caracterizados por estructuras severas en el cuadrante noreste peninsular, es posible relacionar las imágenes de radar de dichos episodios con la situación meteorológica existente a través de campos de reanálisis y observaciones.

Este estudio presenta un breve análisis del entorno sinóptico y mesoescalar de dos de esos episodios a través de campos de reanálisis de modelos así como de observaciones convencionales. En el caso del primer episodio también se muestran impactos a partir de datos de observación en superficie y de la información introducida en el sistema de AEMET SINOBAS (Sistema de notificación de observaciones atmosféricas singulares) (RIESCO et al., 2014).

\section{EPISODIOS ANALIZADOS}

\subsection{Episodio 1: 3 de octubre de 2013. Navarra}

Durante la tarde del 3 de octubre y la madrugada y la mañana del 4 de octubre de 2013 se produjo el desarrollo y propagación de estructuras convectivas con efectos potencialmente severos tanto en la Comunidad Foral de Navarra como en la comarca de las Cinco Villas de Aragón y el Pirineo occidental. Por ejemplo, en las localidades zaragozanas de Biota, Pinsoro y Sádaba se ha analizado y documentado la ocurrencia de rachas de viento huracanadas que causaron alto impacto y destrozos de consideración en la madrugada del 4 de octubre (SAN Ambrosio y LóPEZ LóPEZ, 2014).

En el caso de Navarra la mayor severidad se produjo entre las 18 y las 20 UTC del día 3 al tener lugar un storm-splitting en el tercio sur de la Comunidad Foral. Como es habitual en procesos convectivos de este tipo en el cuadrante noreste peninsular, la helicidad de la tormenta fue favorable al miembro ciclónico (right mover) que se propagó en dirección suroeste-noreste atravesando todo Navarra. El rápido movimiento de las dos supercélulas fue asimismo destacable: examinando el movimiento de las células en imágenes conse-

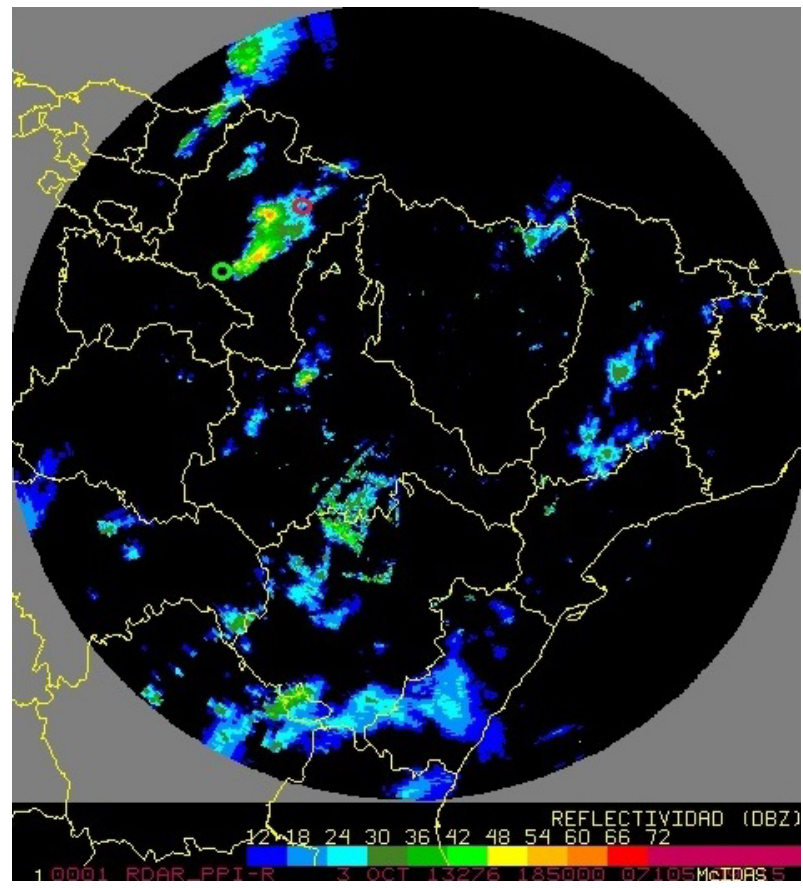

Figura 1. Imagen PPI del radar de Zaragoza a las 18.50 UTC del día 3 de octubre de 2013. El círculo rojo indica la situación de la localidad de Monreal y el círculo verde la posición del sondeo de la figura 6 . cutivas de radar es posible estimar la velocidad de propagación de cada uno de los miembros. Para el miembro anticiclónico la velocidad fue cercana a los $80 \mathrm{~km} / \mathrm{h}$ mientras que para el ciclónico próxima a $45 \mathrm{~km} / \mathrm{h}$. En la figura $1 \mathrm{se}$ muestra una imagen PPI del radar de Zaragoza a las 1850 UTC del día 3 de octubre.

En el mapa de 500 hPa de las 18 UTC del día 3 de octubre (figura 2) se observa la situación sinóptica correspondiente, caracterizada por una marcada vaguada al oeste de la Península con eje aproximadamente meridiano, aunque ligeramente inclinado hacia el suroeste y con una masa de aire frío asociada $\left(-16,-18{ }^{\circ} \mathrm{C}\right.$, aproximadamente). La vaguada se desplazó hacia el este penetrando en el interior peninsular. En el mapa se aprecian ligeras ondulaciones en el flujo general del suroeste que provocan difluencias en la región de salida de la vaguada al atravesar la zona de estudio. Por otro lado, hay un transporte de humedad desde el suroeste en el nivel de $850 \mathrm{hPa}$ y desde el sureste en el de $925 \mathrm{hPa}$ (figura 3 ). 


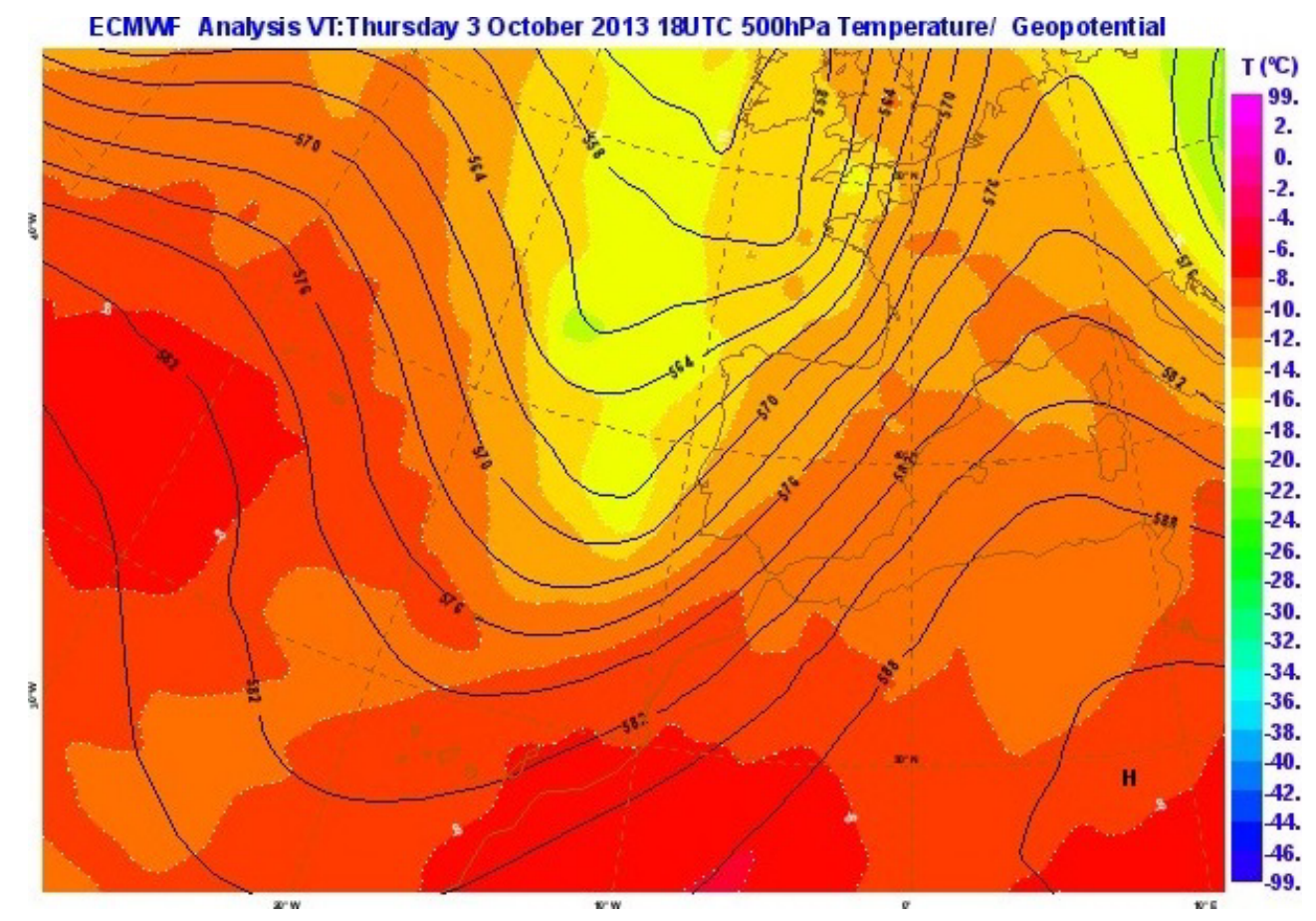

Figura 2. Mapa de altura geopotencial y temperatura en el nivel de $500 \mathrm{hPa}$ para el 3 de octubre de 2013 a las 18 UTC.
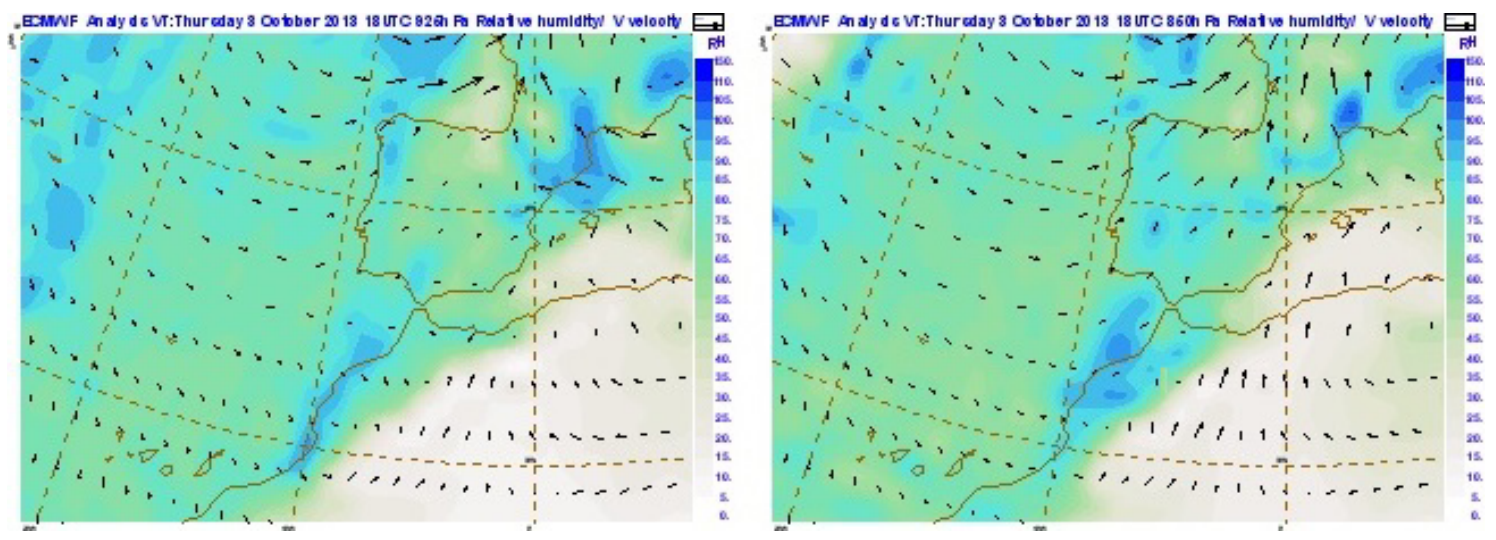

Figura 3. Mapa de humedad relativa y velocidad del flujo en el nivel de $925 \mathrm{hPa}$ (izquierda) y $850 \mathrm{hPa}$ (derecha) para el 3 de octubre de 2013 a las 18 UTC.

A continuación se enumeran características de la situación meteorológica relacionadas con la convección y se ilustran mediante sondeos, campos de inestabilidad termodinámica o de humedad, convergencias en niveles bajos, etc.:

1) Los campos asociados a la inestabilidad termodinámica en la zona donde se produjo el storm-splitting y la posterior propagación de las supercélulas muestran valores significativos. Para el CAPE (campo que no solo tiene en cuenta la inestabilidad térmica sino también la humedad y además es muy sensible a las condiciones iniciales en la evolución de la burbuja) resultan cantidades que rondan los 1200-1400 J/kg. El modelo HRES-IFS del ECMWF proporciona el CAPE más inestable en el estrato atmosférico correspondiente a los $350 \mathrm{hPa}$ más próximos a la superficie. El gradiente térmico vertical (GTV) en el estrato entre 800 y $600 \mathrm{hPa}$ (aproximadamente entre 2 y $4 \mathrm{~km}$ ) se encuentra en torno a $7,5^{\circ} \mathrm{C} / \mathrm{km}$, pudiéndose considerar moderadamente inestable.

Ambas variables se representan en la figura 4. 


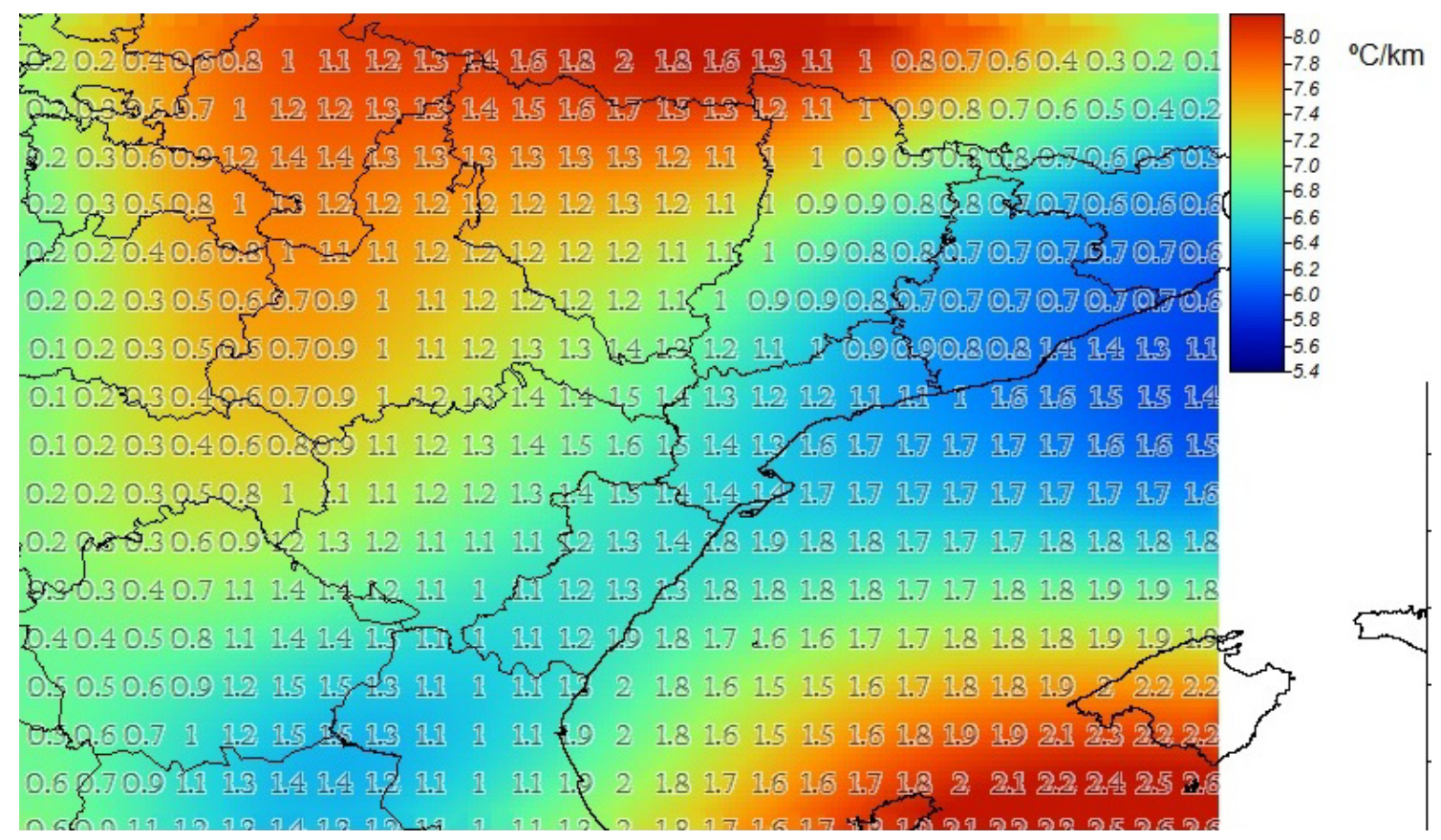

Figura 4. GTV en el estrato entre 800 y $600 \mathrm{hPa}$ (colores) y CAPE en kJ/kg (números) obtenidos del reanálisis ERA-Interim para las 18 UTC del 3 de octubre de 2013.

2) Se observa una gran convergencia de humedad en todo el valle del Ebro, si bien es mayor en el tramo medio y bajo del valle, especialmente entre Zaragoza y Tortosa (con valores cercanos a los $10 \mathrm{~g} \mathrm{~kg}^{-1} \mathrm{~s}^{-1}$ para el promedio en los niveles de 1000, 950, 925 y $850 \mathrm{hPa}$ ). En la Ribera de Navarra los valores oscilan entre 6 y $7 \mathrm{~g} \mathrm{~kg}^{-1} \mathrm{~s}^{-1}$. En cualquier caso los valores de agua precipitable en columna se sitúan por encima de $30 \mathrm{~mm}$ en las trayectorias de propagación de las supercélulas e incluso en los valles del Pirineo navarro se acercan a $35 \mathrm{~mm}$. Ambas variables se representan en la figura 5.

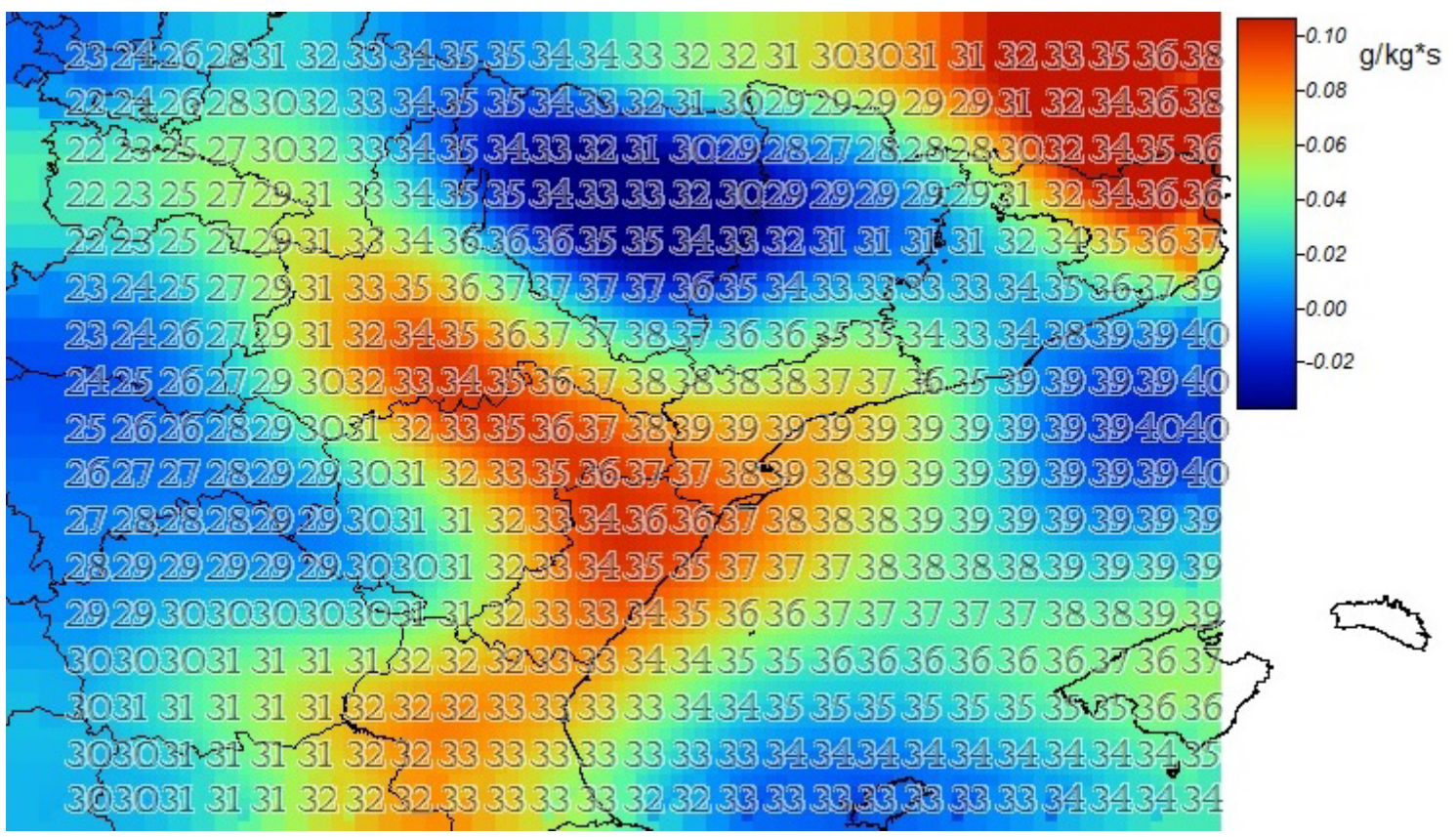

Figura 5. Convergencia de humedad en niveles bajos (colores) y agua precipitable en columna en mm (números) obtenidos del reanálisis ERA-Interim para las 18 UTC del 3 de octubre de 2013. 


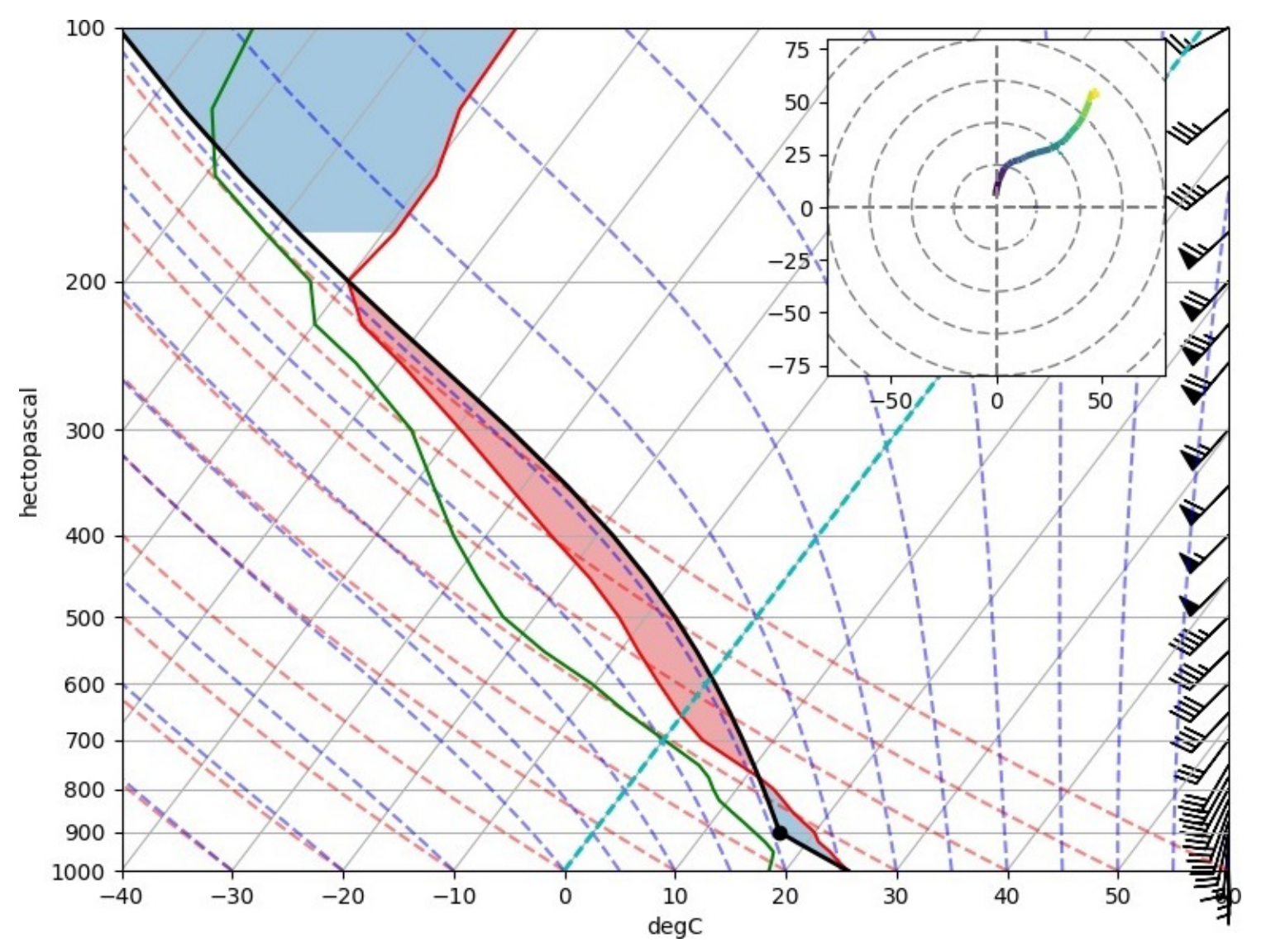

Figura 6. Sondeo y hodógrafa extraídos del reanálisis ERA-Interim para las 18 UTC del 3 de octubre de 2013 en el punto marcado con un círculo verde en la figura 1.

3) Como se muestra en la figura 6, el sondeo y hodógrafa extraídos del reanálisis en un punto cercano a donde se produjo el storm-splitting (véase figura 1), la convección es profunda y el giro del viento es marcado favoreciendo la organización. Los valores de cizalladura entre 0 y $6 \mathrm{~km}$ son suficientemente altos (próximos a $25 \mathrm{~m} / \mathrm{s}$ ) para generar estructuras organizadas o incluso muy organizadas como supercélulas.

En cuanto a la observación en superficie, en Monreal (valle de Elorz, zona media de Navarra) se registraron casi $50 \mathrm{~mm}$ en una hora al paso del miembro con rotación ciclónica. En la figura 1 se ha señalado con un círculo rojo la ubicación aproximada de esta localidad. Dos medidas diezminutales superaron los 15 mm y la fuerte lluvia provocó la interrupción del tráfico en la autovía del Pirineo a la altura de la citada localidad debido a la formación de balsas de agua. En la estación manual de Monreal, sin embargo, se acumularon $75 \mathrm{~mm}$, muy probablemente en menos de una hora y rebasándose el umbral de aviso rojo por precipitación torrencial. La estación manual se encuentra en el núcleo urbano, algo alejada de la automática. Otros registros llamativos asociados al paso de la supercélula son $32 \mathrm{~mm}$ en 30 minutos en Barasoain (comarca de la Valdorba), 54 mm en 30 minutos en Aos (valle de Lónguida, Prepirineo navarro) y 37 mm en 15 minutos en Izalzu (valle de Salazar, Pirineo navarro), todos ellos medidos en estaciones de la Confederación Hidrográfica del Ebro. Pese a que, en un gran porcentaje, las supercélulas llevan asociados fenómenos severos en superficie en forma de tornados, granizo de gran tamaño o vientos muy intensos probablemente estemos ante una supercélula de alta precipitación, dadas las elevadas cantidades recogidas en poco tiempo y su potencial riesgo de crear inundaciones rápidas. (Quirantes et al., 2014; MARKOWSKi y Richardson, 2010; DoswelL, 1993; Doswell et al., 1996; JunKer et al., 1999).

El impacto fue además considerable en Tafalla (zona media de Navarra), donde también se dieron precipitaciones súbitas torrenciales y se reportaron inundaciones en pasos a nivel, bajeras y garajes. Tanto los medios de comunicaciones locales como el reporte introducido en SINOBAS dieron cuenta de ello (figura 7). 


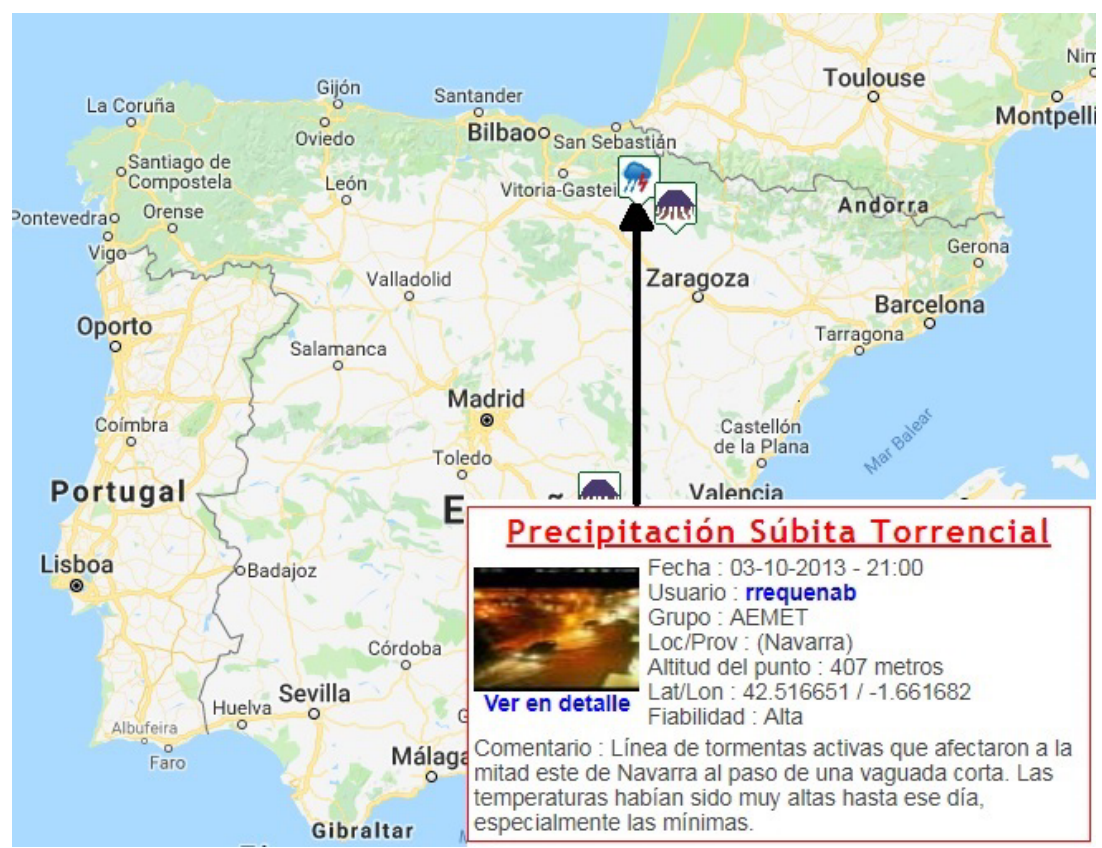

\section{Figura 7.}

Reporte introducido en SINOBAS sobre el impacto de la tormenta en Tafalla y datos de la EMA de AEMET en Monreal con dos registros diezminutales consecutivos superando los $15 \mathrm{~mm}$.

\subsection{Episodio 2: 10 de julio de 2013. Somontano, Hoya de Huesca y Noguera leridana}

La situación sinóptica el 10 de julio de 2013 estuvo marcada por una vaguada en altura con eje en dirección suroeste-noreste que se extendió desde el Cantábrico hasta Centroeuropa. Se produjeron divergencias en el nivel de $300 \mathrm{hPa}$ en el noreste peninsular. A ello se sumó que la baja térmica peninsular potenció una advección húmeda en la costa mediterránea, el Pirineo y Prepirineo. Estas dos características de la situación se ilustran en la figura 8 .
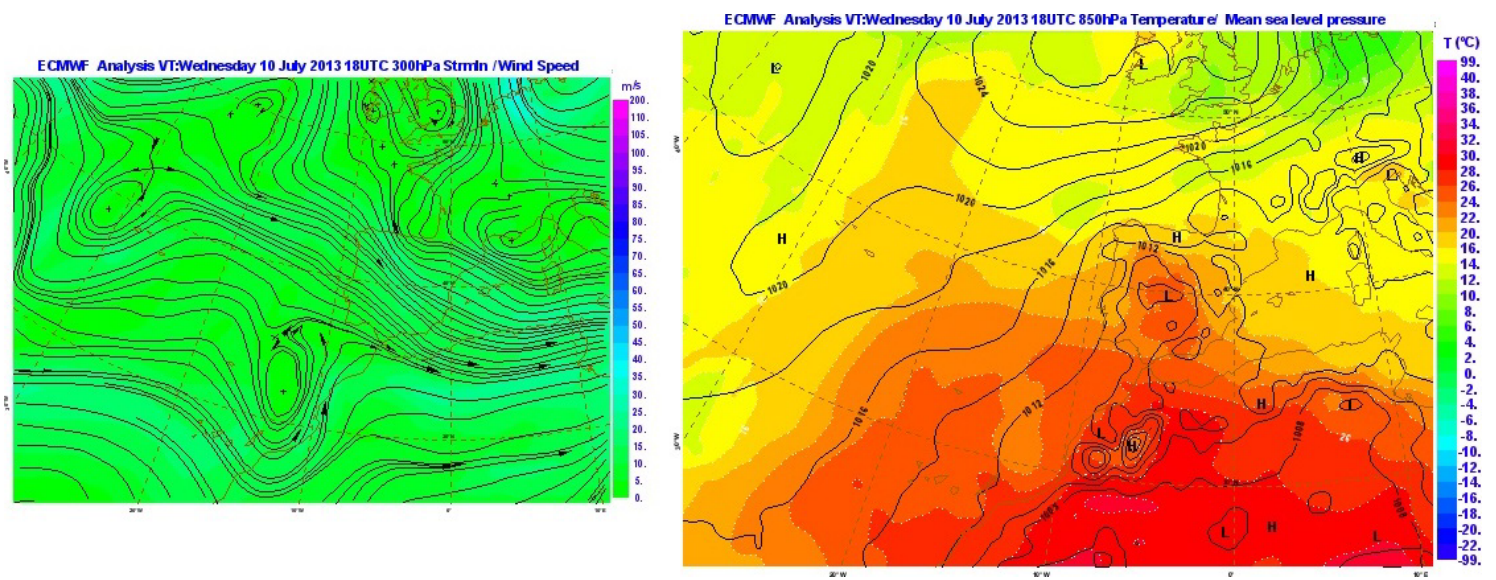

Figura 8. Mapa de líneas de flujo en el nivel de $300 \mathrm{hPa}$ (izquierda) y presión media a nivel de superficie (derecha) para el 10 de julio de 2013 a las 18 UTC.

De este episodio destaca además la baja intensidad de los vientos y la cizalladura en los niveles de 850 y $700 \mathrm{hPa}$. Es sabido que esta circunstancia puede contribuir a que las estructuras convectivas sean lentamente móviles y se generen células semiestáticas sobre todo si el aporte húmedo a nivel local está favorecido por la orografía o las convergencias (JuNKER et al., 2017). El riesgo principal de este tipo de estructuras es que generen precipitaciones de gran intensidad durante un intervalo temporal que pueda abarcar una o varias horas dando lugar a crecidas repentinas en ríos, y torrentes de montaña, especialmente en la época estival u otoñal. En la imagen PPI de las 19.10 UTC del radar de Zaragoza se observa una de esas estructuras cuasiestáticas (figura 9). En el sondeo de la figura 10, se puede apreciar además un perfil saturado en el 
Figura 9.

Imágenes PPI del radar de Zaragoza a las 1910 UTC del día 10 de julio de 2013. El círculo rojo indica la posición aproximada del sondeo de la figura 10.

Figura 10.

Sondeo y hodógrafa extraídos del reanálisis ERA-Interim para las 18 UTC del 10 de julio de 2013 en el punto marcado con un círculo rojo en la figura 9.
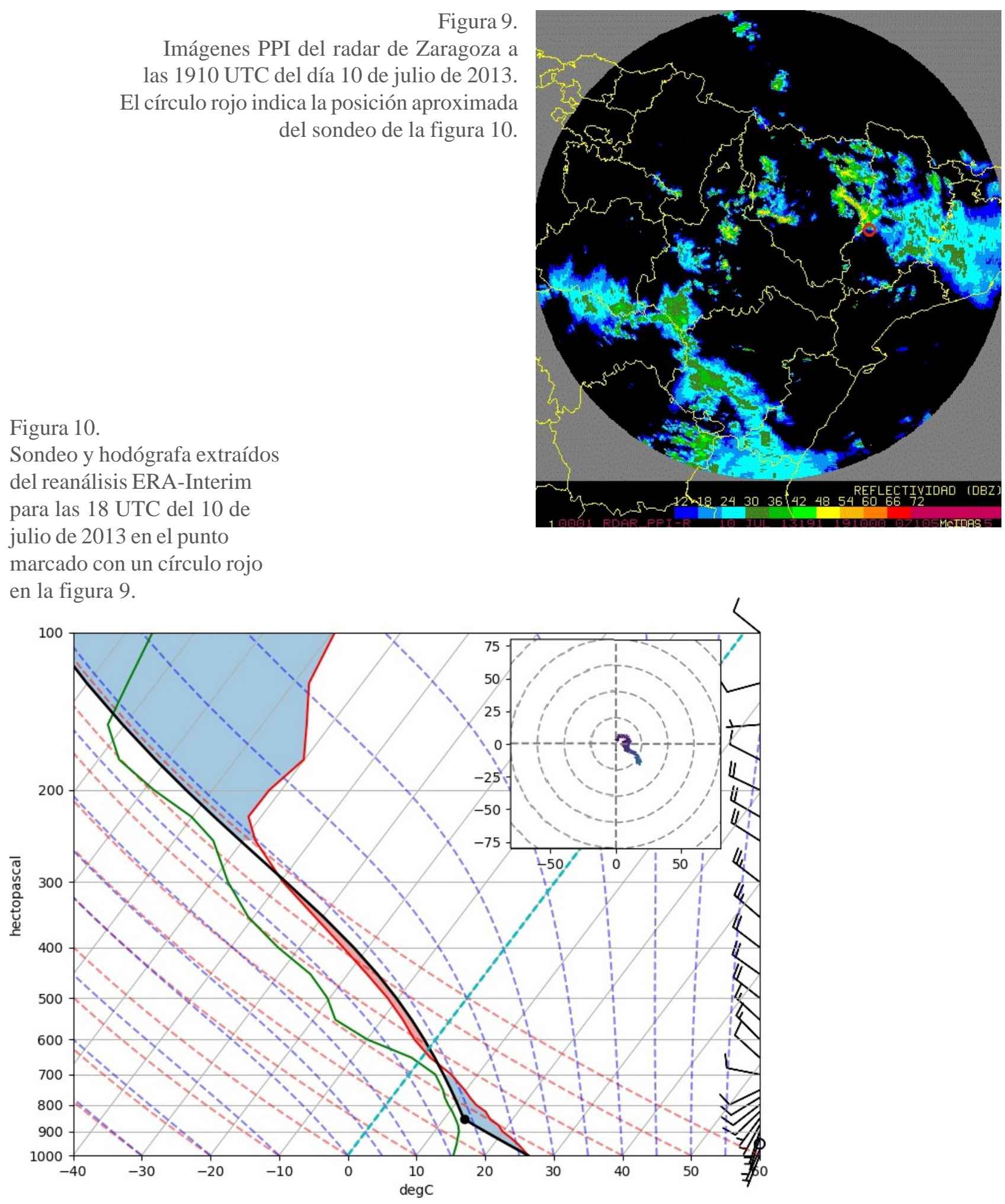

estrato 850-700 hPa caracterizado por un flujo húmedo de oeste-noroeste en altura y de sur-suroeste en niveles bajos. Al igual que en el caso del episodio 1 se enumeran algunas características obtenidas del análisis de campos meteorológicos que pueden estar relacionados con la convección severa:

1) El GTV en el estrato entre 800 y $600 \mathrm{hPa}$ ronda los $7^{\circ} \mathrm{C} / \mathrm{km}$, suficientemente inclinado como para considerarse inestable. El CAPE ronda los $1000 \mathrm{~J} / \mathrm{kg}$ (figura 11.a). La advección húmeda en niveles bajos (promedio en los niveles de 1000, 950, 925 y $850 \mathrm{hPa}$ ) es notable, cercana a los $9-10 \mathrm{~g} \mathrm{~kg}^{-1} \mathrm{~s}^{-1}$ por cada $100 \mathrm{~km}$ y los valores de agua precipitable en columna se encuentran próximos a los $30 \mathrm{~mm}$ (figura 11.b). 

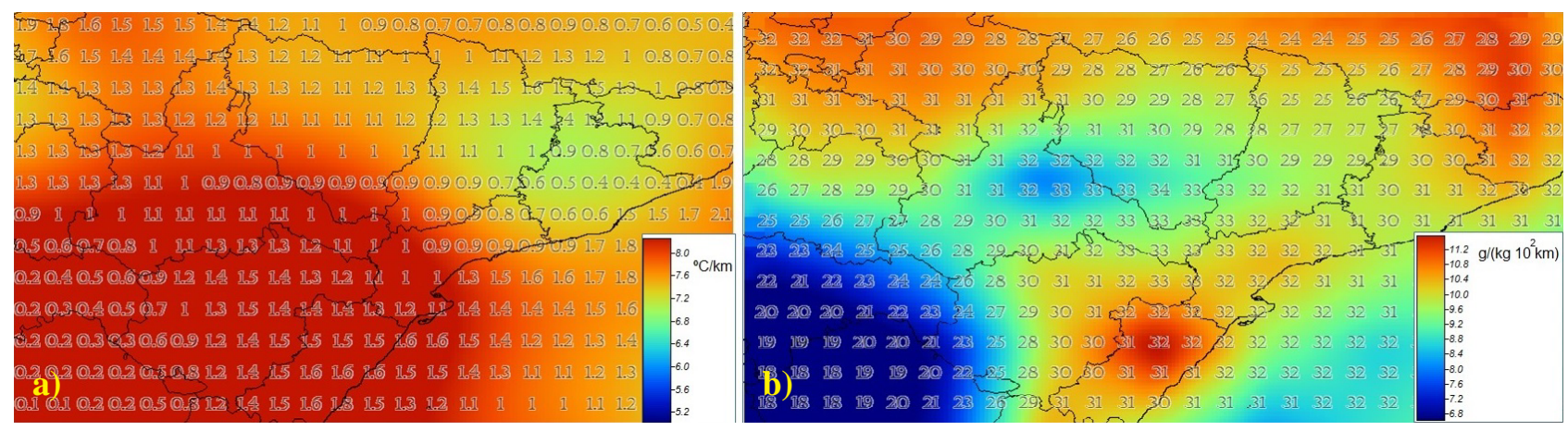

Figura 11. a) GTV en el estrato entre 800 y $600 \mathrm{hPa}$ (colores) y CAPE en kJ/kg (números).

b) Advección húmeda en niveles bajos en $\mathrm{g} \mathrm{kg}^{-1} \mathrm{~s}^{-1}$ (colores) y agua precipitable en mm (números).

Todos los campos han sido obtenidos del reanálisis ERA-Interim para las 18 UTC del 10 de julio de 2013.

2) Otro de los campos que se ha analizado en la zona de estudio es el gradiente de temperatura potencial equivalente. En la figura 12 se observan valores cercanos a $5^{\circ} \mathrm{C} / 100 \mathrm{~km}$ en la zona de estudio, suficientemente grandes como para indicar una frontera entre masas de aire en la zona de formación de tormentas.

3) Si bien la cizalladura no es suficientemente importante como para dar lugar a grandes estructuras organizadas sí que se forman algunos grupos de tormentas con estructuras definidas, el más importante en la zona de Os de Balaguer (aproximadamente coincidente con el punto del sondeo de la figura 10), que avanza lentamente en dirección noroeste-sureste y que produce las precipitaciones más significativas en forma de chubascos intensos como se ha indicado anteriormente.

En cuanto a la observación en superficie destacan dos valores diezminutales de precipitación que rebasan los $20 \mathrm{~mm}$ en la EMA leridana de Os de Balaguer, sumado al hecho de que los chubascos se mantienen activos durante varias horas.

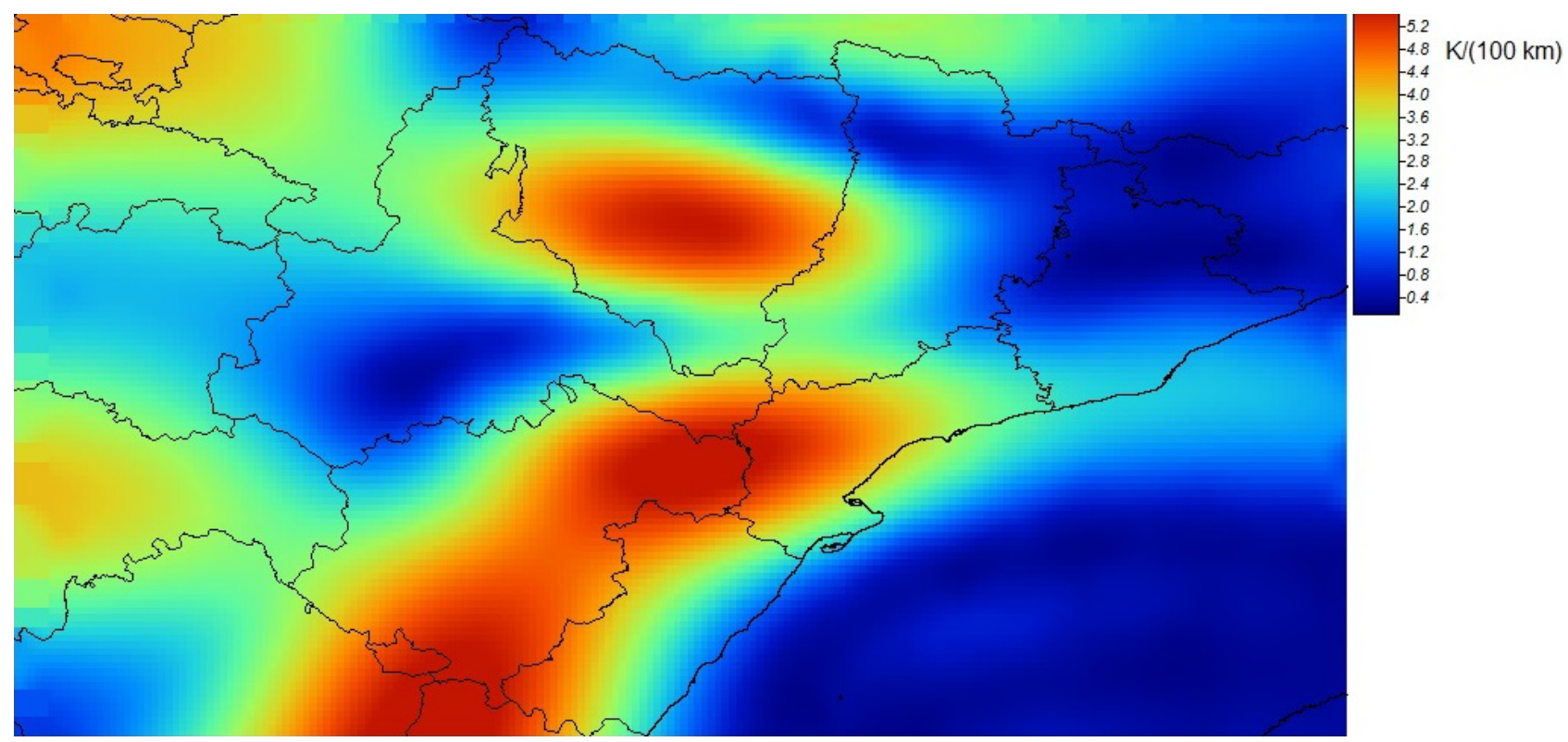

Figura 12. Gradiente de temperatura potencial equivalente obtenido del reanálisis ERA-Interim para las 18 UTC del 10 de julio de 2013. 


\section{CONCLUSIONES}

Los episodios descritos constituyen tan solo dos muestras del gran número de situaciones convectivas severas que se producen en el cuadrante nororiental de la península ibérica en la época estival, a finales de primavera o a principios de otoño. Los episodios analizados se caracterizan por dar lugar a precipitaciones de alta o muy alta intensidad debido al paso de una tormenta supercelular (caso del primer episodio) y a la semiestacionariedad de un grupo de tormentas alineadas (segundo episodio). Estos episodios tuvieron lugar en octubre y julio de 2013, sin embargo, en años como 2014 o 2018 se ha registrado un mayor número de tormentas que han originado efectos severos, de acuerdo a la evolución temporal de las climatologías de reflectividad radar obtenidas en la contribución «Climatología de células convectivas con efectos severos asociados en el noreste peninsular».

Puesto que es posible extraer un histórico de las células convectivas más severas (mediante el tratamiento de las imágenes de radar), se podría recopilar un repertorio de situaciones convectivas con efectos severos asociados en esta parte de la Península y los campos de reanálisis correspondientes que puedan ser más concluyentes en cada uno de los casos para el pronóstico de los efectos de la convección profunda y/o organizada. Algunos de esos campos se han mostrado en esta contribución, por ejemplo, parámetros de inestabilidad como el CAPE, el GTV, o la advección y convergencia de humedad en niveles bajos o los propios sondeos y hodógrafas construidos mediante los distintos campos de reanálisis. Este repertorio podría tener usos formativos o dar lugar a un mejor estudio y conocimiento de la convección severa en la península ibérica, más allá del pronóstico puntual o el seguimiento y vigilancia que se lleva a cabo operativamente. Similarmente podría ser interesante ligar la evolución temporal del número anual de tormentas severas en el cuadrante noreste peninsular con patrones y tendencias climáticas a través de índices (como el de la NAO, la circulación de las ondas de Rossby, la frecuencia de patrones de bloqueo o estructuras omega, etc.).

\section{REFERENCIAS}

Pascual, R., Cuevas, G. y Viana, S. A., 2014. Análisis de un complejo episodio de tiempo muy adverso en el este de la Península Ibérica y Baleares. https://repositorio.aemet.es/bitstream/20.500.11765/1336/1/ Episodio_tiempo_adverso_noviembre_2013.pdf.

Pascual, R., Cuevas, G. y González Herrero, R., 2015. Estudio de la situación de tiempo adverso del 1 y 2 de agosto de 2014 en el nordeste peninsular. Nota técnica 16 de AEMET.

SAn Ambrosio, I. y LóPEz LóPez, B. P., 2014. Informe sobre las rachas de viento huracanadas asociadas a la convección profunda y muy organizada del día 4 de octubre de 2013 en Biota (Zaragoza). Documento interno de AEMET.

Riesco, J., Díez, E, Gutiérrez, D., Ponce, S., García, T., Flores, C., Núñez, J. A., Prieto, T., SÁnchez-Laulhé, J. M. y Martín, F., 2014. Sistema de Notificación de Observaciones Atmosféricas Singulares (SINOBAS). XXXIII Jornadas Científicas de la AME, Asociación Meteorológica Española.

Quirantes, J. A., Riesco, J. y NúÑEz, J. A., 2014. Características básicas de las supercélulas en España. AEMET. http://www.aemet.es/documentos/es/conocermas/recursos_en_linea/publicaciones_y_estudios/ publicaciones/Caracteristicas_supercelulas/Caracteristicas_supercelulas.pdf.

Markowski, P. y Richardson, Y., 2010. Mesoscale meteorology in midlatitudes. Ed. Wiley-Blackwell.

Doswell, C.A., 1993. Flash Flood-Producing Convective Storms: Current Understanding and Research. Reprinted from Proceedings, Spain-U.S. Joint Workshop on Natural Hazards, Barcelona, Spain, 8-11 June 1993. 
Doswell, C. A., Maddox, R. A., y Brooks, H. E., 1996. Flash Flood Forecasting: An Ingredients-Based Methodology. Weather and Forecasting, 11, 560-581.

Junker, N. W., Schneider, R. S. y FAuver, S. L., 1999. A Study of Heavy Rainfall Events during the Great Midwest Flood of 1993. Journal of American Meteorological Society, 14, 701-714. 